\title{
Explanations for use of dietary- and muscle enhancing dietary supplements among university students: a national cross-sectional study
}

\author{
Christine Sundgot-Borgen ${ }^{1,2^{*}}$, Therese Fostervold Mathisen ${ }^{3}$, Monica Klungland Torstveit ${ }^{4}$ and \\ Jorunn Sundgot-Borgen ${ }^{1}$
}

\begin{abstract}
Background: Use of dietary supplements (DS) and muscle enhancing dietary supplements (MEDS) is frequent among students despite the lack of evidence of effects and health risks related to consumption. We need to increase our understanding of students' motivation, examine potential gender differences, and explore explanatory factors, to address preventive measures related to use. Therefore, this study aimed to explore the frequency of, and the reasons for, DS use among university students, as well as explanatory factors for use of MEDS.
\end{abstract}

Method: Male and female students from nine Norwegian universities participated in this cross-sectional study. Participants responded to questions about demographics, DS and MEDS use, internalization of body ideals, physical activity- and exercise level, motives for exercise, and exercise context. Independent t-test, Chi-square test, Pearson's correlation, and logistic regression were used to investigate between group differences, associations, and explanatory factors for use, respectively. $P$-values $\leq 0.05$ were defined as significant.

Results: A total of 1001 males (34\%) and females, with a mean(sd) age of 24.21(4.76) years, participated. The frequency of DS use was $42 \%$ and $40 \%(p=.414)$ in males and females, respectively, in which more males than females used DS to improve physical or mental performance $(p=<.001)$, increase muscle mass $(p=<.001)$ and weight for health $(p=.014)$, and improve appearance $(p=<.001)$. In males and females, respectively, $25 \%$ and $10 \%$ used MEDS $(p=<.001)$. In males, being a fitness center member (OR:3.80), exercising to improve muscle mass (OR:1.96), and a higher physical activity level (OR:1.09) positively explained MEDS use, while exercising to increase endurance (OR:0.49) and being an exercise science student (OR:0.47) negatively explained MEDS use. In females, internalizing the athletic body ideal (OR:1.78) and exercising to improve muscle mass (OR:1.74) positively explained MEDS use.

Conclusions: Our main findings indicate that a surprisingly high percentage of male and female Norwegian students use DS and MEDS, and that reasons for use, and variables explaining the variability in frequency of use, differ between genders. Longitudinal studies to investigate direction of associations are needed in future research.

Keywords: Dietary supplements, Muscle enhancing supplements, Students, Body idealization, Internalization, Exercise science

\footnotetext{
${ }^{*}$ Correspondence: christine.sundgot-borgen@psykologi.uio.no

1 Department of Sports Medicine, Norwegian School of Sport Sciences,

Sognsveien 220, N-0806 Oslo, Norway

Full list of author information is available at the end of the article
}

(C) The Author(s) 2022. Open Access This article is licensed under a Creative Commons Attribution 4.0 International License, which permits use, sharing, adaptation, distribution and reproduction in any medium or format, as long as you give appropriate credit to the original author(s) and the source, provide a link to the Creative Commons licence, and indicate if changes were made. The images or other third party material in this article are included in the article's Creative Commons licence, unless indicated otherwise in a credit line to the material. If material is not included in the article's Creative Commons licence and your intended use is not permitted by statutory regulation or exceeds the permitted use, you will need to obtain permission directly from the copyright holder. To view a copy of this licence, visit http://creativecommons.org/licenses/by/4.0/. The Creative Commons Public Domain Dedication waiver (http://creativeco mmons.org/publicdomain/zero/1.0/) applies to the data made available in this article, unless otherwise stated in a credit line to the data. 


\section{Background}

\section{Dietary supplement use among university students}

Dietary supplements (DS) are generally defined as products which are orally consumed and aim to supplement one's diet [1]. Studies show that higher education level is associated with more DS use compared to lower education level [2-4]. In fact, $43-80 \%$ of male and female American, Australian, and Canadian university students report use of DS, with use of vitamins/minerals, muscle enhancing dietary supplements (MEDS) (such as protein, creatine, amino acids), weight loss supplements, and herbs, being the most commonly reported [2, 5-9]. The most frequently reported reason for use is related to health promotion, followed by providing more energy, enhancing sport performance, and appearance improvement [2, 5, 9-11]. DS use among university students is associated with higher levels of physical activity, and lower body mass index (BMI) $[5,6,9,12,13]$, and most studies report no gender difference in frequency of use $[5,6,11,13,14]$.

The high frequency of DS use among students exists despite the scarce evidence on the efficacy and acute and long-term health effects from using such supplements [15]. This is a concern as public health guidelines do not include the use of DS, and use might therefore potentially increase the risk of an intake above the safety limits of various nutrients [16]. MEDS especially, have gone through poor quality control and have been found harmful due to contamination of illegal substances [17, 18]. Use of MEDS is also worrying because it is related to body image issues [19], which has been related to increased stress level and reduced quality of life in youth [20] and to reduced mental health in university students [21].

\section{The athletic body ideal and muscle enhancing dietary supplements}

Unfortunately, especially within the marketing of MEDS, there is a strong idealization of extreme athletic bodies which facilitates internalization of these unhealthy and unrealistic ideals. Internalization of this specific ideal has been found to increase upward appearance comparison and body dissatisfaction in undergraduate males [22] and females [23] and might strengthen the perceived need to use supplements to obtain the internalized body type. In fact, studies on adolescents show that frequent users of MEDS are characterized by high scores on internalization of the athletic body ideal [24-26].

Parallel to the increased focus on the athletic body as a health ideal, the prevalence of older adolescents [27] and young adults [28] being a member at a fitness center has exploded. The fitness center environment is associated with pressure to comply with the athletic body ideal [21, 29, 30]. Also, fitness centers sell MEDS and are believed to stimulate use among members [31]. In support of this, studies have found that Norwegian adolescents [24], and American and Brazilian adults $[31,32]$, who were members at a fitness center, are frequent users.

Studies have also found that male and female students representing health related study programs report less use of DS in general compared to students in nonhealth related programs $[7,9,33]$, while others find the opposite $[10,11,13,34]$. However, previous studies have not focused on the use of MEDS, and students attending health focused exercise science study programs have not been included into studies comparing the influence of study program on DS use. Due to their health-, physical exercise-, and performance focused educational background, one might argue that exercise science students' attitudes and behaviors related to MEDS would differ from those of other health-and non-health related-students.

Due to the potential physical and mental health risk of using DS in general, continuous tracking to evaluate trends in DS use among students, seems important. Studies on Nordic students are lacking, and further investigation of gender differences is needed. Finally, to our knowledge, no studies have investigated whether internalization of the athletic body ideal, being a fitness center member, or being an exercise science student or not, might be explanatory factors for the use of MEDS among university students.

Therefore, this study aimed to explore 1) the frequency of, and 2) the reasons for DS use among male and female university students. We also aimed to 3 ) explore the frequency of and identify variables explaining the variability in frequency of MEDS use, specifically evaluating internalization of body ideals, exercise context (i.e., participating in organized sports or being a fitness center member), study program (being an exercise science student or not), physical activity and exercise level, and motives for exercise, in both male and female university students.

\section{Method \\ Study design}

This study is a part of a large cross-sectional study where the overall aim was to explore the level and associations of body appreciation, body appearance pressure, body image related mental health constructs, physical activity and exercise level, and DS use in Norwegian university students [21]. Data on demographics, different aspects of DS use, physical activity and exercise, and internalization, are included in this current study. 


\section{Participants}

To achieve good representability of both exercise science, and non-exercise science students in Norway, nine universities from large cities, representing higher education campuses in all cardinal areas in Norway, offering exercise science and/or non-health related study programs, were contacted and asked to participate in the study. Eligibility criteria were being male and female students who understood Norwegian writing. Participants represented students enrolled in a bachelor's or master's degree in exercise sciences, teaching, engineering, or business and administration. Students were split into "male" $(n=335)$ and "female" $(n=666)$ to investigate gender differences, and either "exercise science students" $(n=517)$ or "other students" $(n=476)$, to investigate explanatory factors for MEDS use.

\section{Data collection}

After consent from the dean at each university, the contact person at each universities' faculties representing 1) exercise science programs and 2) non-exercise science or non-health related study programs, were asked if their students could be contacted by the research team. Students were then informed about the study and asked to participate through their student e-mail and web-based learning management systems. Students were recruited during the period of January-June 2020 and responded once to an electronic questionnaire. Prior to answering the questionnaire, students were informed about the overall aim of the study, and that participation would take about $15 \mathrm{~min}$.

\section{Demographics}

Students self-reported age, gender, height and weight, scientific study program (recoded into being an exercise science student (1) or not (0)), as well as immigration status, where having two parents immigrated defined a student with immigration background.

\section{Supplementation}

Use of DS and MEDS were the main outcome variables. Outcomes were measured with self-developed questions on current use of DS (yes $=1$, no $=0)$ and type of DS used (vitamins, minerals, MEDS (protein, creatine, amino acids), fat-burners, dieting aids, herbal products, meal replacements, and sports supplements (e.g., sports drinks, pre-workout, energy boosters, bars)). Students were also asked whether they used any type of DS which they assumed or knew was illegal in Norway (e.g., DS containing growth-hormones, pro-hormones, fat-burners, diuretics, stimulants, or sedatives). We also measured reasons for use of DS and illegal DS, with several response options (to maintain or improve health, improve mental or physical performance, increase muscle mass, reduce fat mass, increase weight for health, reduce weight for health, increase and reduce weight for appearance reasons). Students were free to report more than one type of DS and reason for use. To provide a more logical presentation of correlations and analyses evaluating explanatory factors for use of MEDS, we merged protein, creatine, and amino acid supplementations to one new variable defined as MEDS. Comparably, dieting supplements and fat-burners were merged into the group "Dieting aids".

\section{Physical activity and exercise}

Physical activity was in the questionnaire defined as "all bodily movement that lead to an increase in body temperature, and light-heavy shortness of breath" [35]. Students rated, in hours and minutes, their level of physical activity during the last week. Students also reported number of exercise sessions during the last week, where exercise was defined as "a type of physical activity conducted to maintain or improve physical fitness (e.g., resistance training, cardio). Exercise is more planned than regular physical activity" [35]. Data on physical activity and exercise were treated as continuous data in the analyses.

\section{Motives for exercise}

Through a self-developed questionnaire, students were asked about their motives for exercise and responded to each motive (to prevent illness, reduce body weight, maintain body weight, increase muscle mass, reduce bodyfat percentage, change body shape, increase muscle strength, increase endurance, to perform well in physical activities or sports, because it is fun, it is social, it promotes good mood, to increase energy, reduce bad conscience) on a Likert scale ranging from 1 (highly disagree) to 5 (fully agree).

\section{Exercise context}

Students were asked whether they currently participated in any organized sports (yes $=1$, no $=0$ ) and whether they were members of a fitness center $(y e s=1$, no $=0)$. Students could therefore be categorized as members within both exercise contexts.

\section{Sociocultural attitudes towards appearance questionnaire 4R (SATAQ-4R)}

To assess internalization of body ideals, we used the internalization sub-tests Thin/low body fat internalization, Athletic/muscular internalization, and General attractiveness internalization in the SATAQ-4R [36]. Participants responded to a 5-point Likert-scale ranging 
from 1 (strongly disagree) to 5 (strongly agree), where negatively worded items were reversed and a mean score for each sub-test was calculated. A higher score indicates a higher degree of internalization. We found a good model fit for the current sample, and an $\alpha$ of 0.79-0.87 and 0.810.89 for male and females, respectively. This is similar to reported $\alpha$ in college male and females [36].

\section{Statistical analyzes}

Data were analysed with IBM SPSS version 26. After visually evaluating the data for normality, between group differences were analyzed using student independent t-test for numerical data and Chi-square test for categorical data. The association between variables was evaluated by Person's correlation and Chi-square test for numerical and categorical data, respectively, conducted with bootstrapping with 1000 replications. Correlation coefficients in the areas $0.1,0.3$ and 0.5 were interpreted as weak, moderate, and strong effect sizes, respectively [37]. (Data on group difference between MEDS users and non-users, and correlational data can be found within Additional Table 1 and Additional Table 2, respectively). Direct logistic regression was performed to assess the impact of independent variables (SATAQ, exercise context, study program, BMI, physical activity level, number of exercise sessions, and motives for exercise) on the dependent dichotomous variable use of MEDS. Independent variables which significantly correlated with the dependent variable $(r>0.2)$, and did not strongly correlate among each other, were included into the first regression model. Goodness of fit test is presented with chi-square, degrees of freedom, and significance value. The Cox \& Snell R square and Negelkerke R Square values provide an indication of the amount of variation in the dependent variable explained by the logistic regression model. The predictive value of each independent variable is presented through Odds Ratio (OR). OR above 1 represents a positive correlation, while $<1$ represents a negative correlation between dependent and independent variable within the logistic regression analyses. For the rest of the analyses, data are presented as mean(sd) and number of observants (\%), and effect sizes for group differences by Hedges' $g$ (small: 0.2, medium: 0.5, large: 0.8 ) and Phi-coefficient $(\phi)$ (small: 0.1, medium: 0.3, large: 0.5 ) for numerical and categorical data, respectively. Alpha level was set to $\leq 0.05$. Among all consenting students only one female exercise science student and one female reference student did not fully complete all questions. Therefore, no dropout differences were investigated.

\section{Ethics}

The study was conducted according to the World Medical Association Declaration of Helsinki. It was approved by the Norwegian Regional Committees for medical and health research ethics (No. 33532) and the Norwegian Centre for Research data (No. 978522). The students consented to participate by pressing "yes" to the question of consent in an informative email and were redirected to the online questionnaire which was developed through the web-based system SurveyXact 8.2 offered by Ramböll, Aarhus, Denmark.

\section{Results}

\section{Demographics}

Participant characteristics are presented in Table 1. Among the 5344 students who were informed about the study, a total of 1001 male (335) and female (666) students consented to participate, with variation of number of respondents between variables. The mean (sd) age and BMI of the total sample was 24.21 (4.76) years and 24.18 (4.02) $\mathrm{kg} / \mathrm{m}^{2}$, respectively, and in total, $9.5 \%$ of all students reported immigration background.

\section{Frequency of dietary supplement use}

Vitamin, mineral, and protein supplement use was more frequent compared to other types of supplements (Table 2). The use of MEDS and sports supplements were more frequent in male compared to female students $(p=<0.001)$ (Table 2). Due to the low frequency of dieting aids use among males and females, associations with, and explanations for, use of such supplements were not investigated further.

\section{Reasons for dietary supplement use}

Among all response categories, "to maintain or improve health", followed by "to improve mental or physical performance", and "to increase muscle mass", stood out as the most frequently reasons for use of DS among students regardless of gender (Fig. 1). More males than females reported to use supplements to improve physical or mental performance $(p=<0.001, \phi=0.17)$, to increase muscle mass $(p=<0.001, \phi=0.19)$, to increase weight for health $(p=0.014, \phi=-0.08)$, and for appearance reasons $(p=<0.001, \phi=-0.17)$ (Fig. 1).

\section{Explanatory factors for use of muscle enhancing dietary supplements \\ Males}

The correlational analyses (see additional Table 2) led to the inclusion of ten factors assumed to predict the use of MEDS. The full model containing all predictors was significant, $x^{2}(10, N=307)=101.34, p=<0.001$, and explained between $28.1 \%$ (Cox and Snell R square) and 40.9\% (Nagelkerke R square) of the variance in MEDS use, and correctly classified $81.8 \%$ of the cases. Hours of physical activity per week, exercising to increase muscle 
Table 1 Participant characteristics presented as means (M) and standard deviation (sd) or total numbers (\%)

\begin{tabular}{|c|c|c|c|c|c|c|}
\hline & \multicolumn{2}{|c|}{ Males } & \multicolumn{2}{|c|}{ Females } & \multirow[t]{2}{*}{$P$} & \multirow[t]{2}{*}{$g / \varphi$} \\
\hline & $N$ & $M(s d)$ & $N$ & $M(s d)$ & & \\
\hline Age & 335 & $24.60(4.83)$ & 666 & $24.02(4.71)$ & .068 & \\
\hline $\mathrm{BMI}\left(\mathrm{kg} \times \mathrm{m}^{2}\right)$ & 334 & $24.55(3.31)$ & 661 & $24.00(4.32)$ & .024 & 0.14 \\
\hline Immigration status & 334 & $32(9.6 \%)$ & 666 & $63(9.5 \%)$ & .951 & \\
\hline \multicolumn{7}{|l|}{ Study program } \\
\hline Exercise science & 333 & $220(66.1 \%)$ & 660 & $297(45.0 \%)$ & $<.001$ & 0.20 \\
\hline Other sciences & 333 & $113(33.9 \%)$ & 660 & $363(55.0 \%)$ & $<.001$ & 0.20 \\
\hline PA, h/wk & 307 & $9.18(6.03)$ & 588 & $7.19(5.83)$ & $<.001$ & 0.34 \\
\hline Exercise sessions/wk & 307 & $6.00(2.80)$ & 589 & $5.23(2.59)$ & $<.001$ & 0.29 \\
\hline Organized sports members & 307 & $137(44.6 \%)$ & 587 & $185(31.5 \%)$ & $<.001$ & 0.13 \\
\hline Fitness center members & 307 & $217(70.7 \%)$ & 587 & $438(74.6 \%)$ & .207 & \\
\hline SATAQ-Athletic ${ }^{*}$ & 311 & $3.12(0.96)$ & 599 & $3.06(0.92)$ & - & \\
\hline SATAQ-Thin ${ }^{*}$ & 311 & $2.25(0.98)$ & 599 & $4.08(0.61)$ & - & \\
\hline SATAQ-General ${ }^{*}$ & 311 & $3.41(0.96)$ & 599 & $2.87(1.03)$ & - & \\
\hline
\end{tabular}

Age: years of age. BMI: body mass index $\left(\mathrm{kg} / \mathrm{m}^{2}\right)$. SATAQ-4R: Social attitudes towards appearance questionnaire-4 revised. *SATAQ-4R includes male and female specific items, and gender differences are therefore not evaluated. PA h/wk: physical activity hours per week. Immigration status: the student and/or both parents have immigrated. A p-value of $\leq 0.05$ is set as statistically significant when comparing two groups. $g$ : Hedges' $g$ represents the effect size for numerical data and $\varphi$ : Phicoefficient represents effect size for categorical data and are only presented where there is a significant group difference

Table 2 Frequency of dietary supplement use among students shown as total number $(\mathrm{N})$ and percentage (\%)

\begin{tabular}{lllll}
\hline & Males & Females & $\boldsymbol{p}$ & $\boldsymbol{\varphi}$ \\
\hline DS & $130(42.3 \%)$ & $232(39.5 \%)$ & .414 & \\
Vitamins and/or minerals & $79(23.6 \%)$ & $194(29.1 \%)$ & .063 & \\
MEDS & $82(24.5 \%)$ & $68(10.2 \%)$ & $<.001$ & $(0.19)$ \\
Protein supplements & $64(19.1 \%)$ & $60(9.0 \%)$ & $<.001$ & $(0.15)$ \\
Creatin & $50(15 \%)$ & $16(2.4 \%)$ & $<.001$ & $(0.24)$ \\
Amino acids & $10(3 \%)$ & $9(1.4 \%)$ & .074 & \\
Sports products $^{\mathrm{a}}$ & $47(14.0 \%)$ & $51(7.7 \%)$ &. $\mathbf{0 0 1}$ & $(0.10)$ \\
Dieting aids $_{\text {Herbal products }}$ & $4(1.2 \%)$ & $8(1.2 \%)$ & $* * *$ & \\
Illegal supplements $^{\mathrm{b}}$ & $6(1.8 \%)$ & $8(1.2 \%)$ & $* * *$ & \\
\hline DSdi*tary & $1(0.3 \%)$ & $2(0.3 \%)$ & $* * *$ & \\
\hline
\end{tabular}

DS dietary supplements; MEDS muscle enhancing dietary supplements. ${ }^{\text {a }}$ Students were asked about their use of sports product beyond protein and creatine supplementation (e.g. sports drinks, pre-workout, energy boosters, bars). ${ }^{b}$ Among different suggested illegal supplements that students could report use of, one male student reported use of growth hormones, while of the two female students reporting use of illegal supplements, central stimuli $(n=2)$, fat burners that were considered illegal $(n=1)$, sedatives $(n=1)$, and narcotics $(n=1)$, were reported. A $p$-value of $\leq 0.05$ is set as statistically significant when comparing two groups. $\varphi$ : Phi-coefficient is only presented where there is a significant group difference. ${ }^{* * *}$ group difference has not been investigated due to small sample size

mass, and being a fitness center member, made significantly positive contributions to the model, while exercising to increase endurance and being an exercise science student made statistical negative contributions to the model (Table 3). Being a fitness center member explained most of the use among male students, with an odds ratio of 3.81, after controlling for all other factors in the model.

\section{Females}

The correlational analyses (see additional Table 2) led to the inclusion of eight factors assumed to predict the use of MEDS. The full model containing all predictors was significant, $x^{2}(7, N=587)=46.66, p=<0.001$, and explained between $7.6 \%$ (Cox and Snell $\mathrm{R}$ square) and 14.9\% (Nagelkerke $\mathrm{R}$ square) of the variance in MEDS use, and correctly classified $88.4 \%$ of the cases. Exercising to increase muscle mass and internalization of the athletic body ideal made significant positive contributions to the model (Table 4). Internalization of the athletic body ideal explained most of the use among female students, with an odds ratio of 1.78 , after controlling for all other factors in the model.

\section{Discussion}

\section{Summary of findings}

This study aimed to explore the frequency of, and reasons for, DS use, and the frequency of, and explanatory factors for use of MEDS specifically, in male and female university students.

Among Norwegian university students, a similar frequency of males (42.3\%) and females (39.5\%) reported use of DS. Most students reported to maintain health, improve physical or mental performance, and to increase muscle mass, as reasons for DS use in general. As many as 1 in 4 males and 1 in 10 females used MEDS, with a significant gender difference. In males, being a fitness center member, exercising to improve muscle mass, and a higher physical activity level, positively explained use of MEDS, while exercising to increase endurance and 


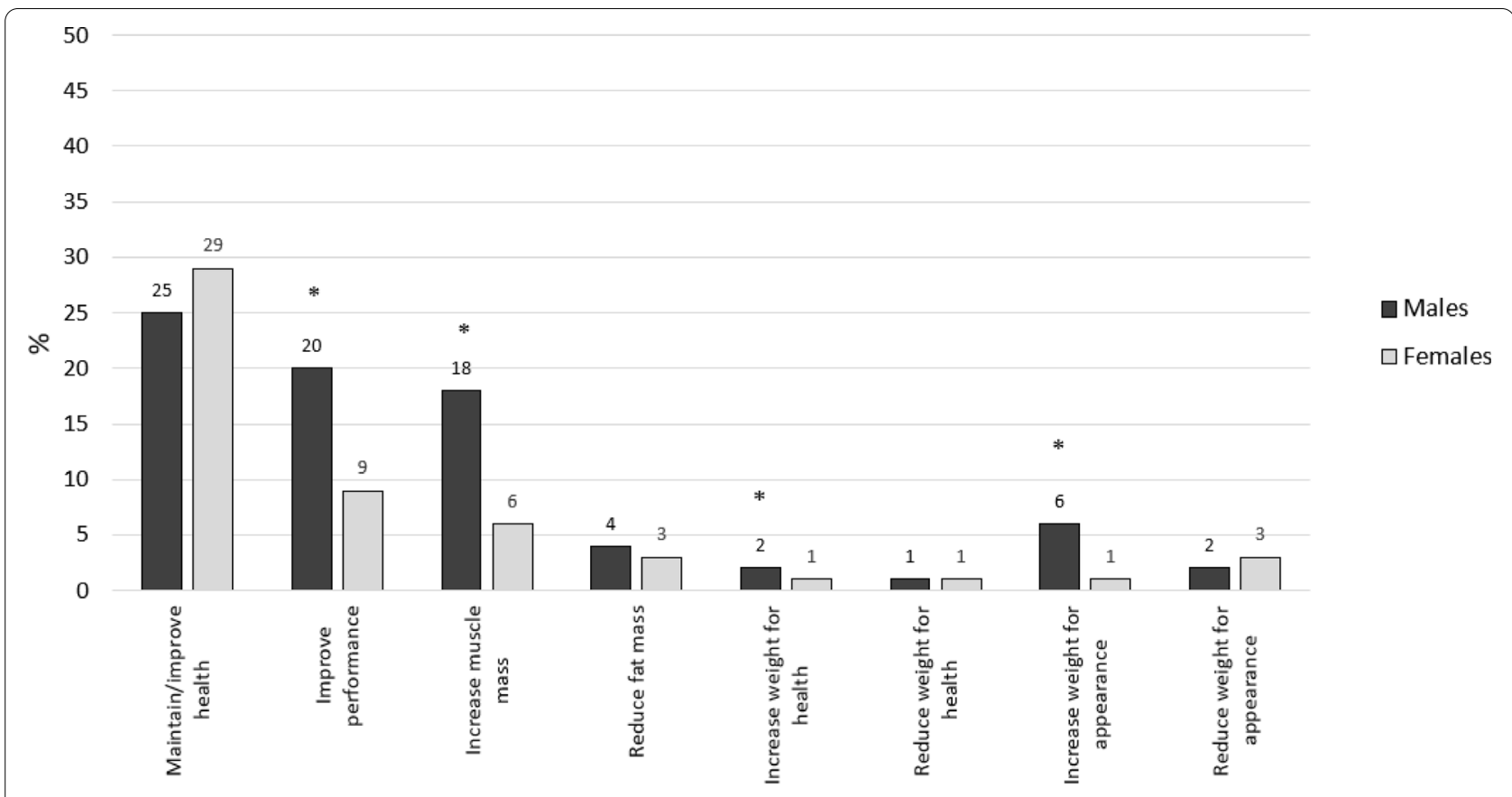

Note: ${ }^{*}$ a $p$-value of $\leq 0.05$ was set as statistically significant when comparing two groups.

Fig. 1 Differences in self-reported reasons for dietary supplement use between male and female university students

Table 3 Logistic regression presenting likelihood of using muscle enhancing dietary supplements in male university students

\begin{tabular}{|c|c|c|c|c|c|c|c|c|}
\hline & \multirow[t]{2}{*}{ B } & \multirow[t]{2}{*}{ S.E } & \multirow[t]{2}{*}{ Wald } & \multirow[t]{2}{*}{ df } & \multirow[t]{2}{*}{$p$} & \multirow[t]{2}{*}{ OR } & \multicolumn{2}{|c|}{ 95\% C.I. for OR } \\
\hline & & & & & & & Lower & Upper \\
\hline Physical activity h/w & 0.08 & 0.03 & 6.08 & 1 & .014 & 1.09 & 1.02 & 1.16 \\
\hline Exercise sessions/w & 0.03 & 0.08 & 0.11 & 1 & .738 & 1.03 & 0.88 & 1.20 \\
\hline Exercise to increase muscle mass & 0.68 & 0.26 & 6.69 & 1 & .010 & 1.96 & 1.18 & 3.27 \\
\hline Exercise to improve strength & 0.38 & 0.32 & 1.44 & 1 & .231 & 1.47 & 0.78 & 2.74 \\
\hline Exercise to enhance endurance & -0.71 & 0.21 & 12.05 & 1 & .001 & 0.49 & 0.33 & 0.73 \\
\hline Exercise to change body shape & 0.12 & 0.17 & 1.41 & 1 & .235 & 1.22 & 0.88 & 1.69 \\
\hline SATAQ Athletic & 0.13 & 0.24 & 0.29 & 1 & .588 & 1.14 & 0.71 & 1.84 \\
\hline Study program ${ }^{\mathrm{a}}$ & -0.76 & 0.35 & 4.58 & 1 & .032 & 0.47 & 0.24 & 0.94 \\
\hline Fitness center member & 1.34 & 0.50 & 7.19 & 1 & .007 & 3.81 & 1.43 & 10.14 \\
\hline Participating in organized sport & 0.39 & 0.38 & 1.02 & 1 & .313 & 1.47 & 0.70 & 3.11 \\
\hline Constant & -5.541 & 1.430 & 15.019 & 1 & .000 & 0.00 & & \\
\hline
\end{tabular}

$h / w$ hours per week. ${ }^{a}$ Being an exercise science student or not. OR above 1 represents a positive correlation, while $<1$ represents a negative correlation between dependent and independent variable

being an exercise science student, negatively explained use of MEDS. In females, internalizing the athletic body ideal and exercising to improve muscle mass positively explained use of MEDS.

\section{Frequency of dietary supplement and muscle enhancing dietary supplement use}

The frequency of DS and MEDS use in our sample is lower than previously reported [2, 5, 7-9]. Differences in
BMI seem not to be explaining these differences, as BMI in the current sample is comparable to previous student samples $[2,5,13,35]$. The differences in use of DS in general, and MEDS in particular, when comparing to other studies, might have been influenced by how "use" was defined, in which our study asked about "current use", while previous studies asked about "the last six months" $[2,7,8]$ or "the past 12 months" [9]. Our results indicate a low frequency of use of illegal DS (0.3\% in both genders), 
Table 4 Logistic regression presenting likelihood of using muscle enhancing dietary supplements in female university students

\begin{tabular}{|c|c|c|c|c|c|c|c|c|}
\hline & \multirow[t]{2}{*}{ B } & \multirow[t]{2}{*}{ S.E } & \multirow[t]{2}{*}{ Wald } & \multirow[t]{2}{*}{ Df } & \multirow[t]{2}{*}{$p$} & \multirow[t]{2}{*}{ OR } & \multicolumn{2}{|c|}{$95 \%$ C.I. for OR } \\
\hline & & & & & & & Lower & Upper \\
\hline Exercise sessions per week & 0.06 & 0.06 & 0.91 & 1 & .339 & 1.06 & 0.94 & 1.18 \\
\hline Exercise to increase muscle mass & 0.55 & 0.26 & 4.40 & 1 & .036 & 1.74 & 1.04 & 2.91 \\
\hline Exercise to improve strength & 0.08 & 0.32 & 0.07 & 1 & .795 & 1.09 & 0.58 & 2.07 \\
\hline Exercise to change body shape & 0.11 & 0.12 & 0.82 & 1 & .364 & 1.11 & 0.88 & 1.40 \\
\hline SATAQ Athletic & 0.58 & 0.20 & 8.19 & 1 & .004 & 1.78 & 1.20 & 2.64 \\
\hline Fitness center member & 0.10 & 0.39 & 0.06 & 1 & .801 & 1.10 & 0.52 & 2.35 \\
\hline Study program ${ }^{a}$ & -0.13 & 0.30 & 0.20 & 1 & .656 & 0.88 & 0.49 & 1.57 \\
\hline Constant & -7.39 & 1.31 & 31.69 & 1 & .000 & 0.00 & & \\
\hline
\end{tabular}

${ }^{a}$ Being an exercise science student or not. OR above 1 represents a positive correlation, while $<1$ represents a negative correlation between dependent and independent variable

which is lower than previous findings among Norwegian males $(2.9 \%)$ and females $(1.0 \%)$ trying out for the military basic training [38].

The lack of gender difference in use of DS in general, echoes what most studies from other countries have found $[5,6,11,13,14]$. However, our study is among few which have investigated gender differences for specific supplements, such as MEDS, and strengthens the assumption that males are more likely to use MEDS than females $[5,8,11]$. This gender difference might reflect a variance in advertisement targeted at males and females [39]. It could also reflect a more prolonged period of muscular body idealization within the history of masculinity, resulting in a more established focus on supplement use to meet this body ideal among males compared to females [40].

\section{Reasons for dietary supplement use}

The most frequent reported reasons for use of DS among our university students, where "to maintain or improve health", "improve mental or physical performance", and to "increase muscle mass", similar to what other student samples have reported [2, 5, 9-11]. In contrast to previous studies, we also looked at gender differences and found that significantly more males compared to females reported use of DS to improve performance and muscle mass, and to increase weight for appearance. This gender difference might underline the under-communicated body appearance pressure among male students [21], and their use of body modification methods.

\section{Explanatory factors for use of muscle enhancing dietary supplements}

Among males, being a fitness center member explained most of the variance in MEDS use, indicated by being four times more likely to use MEDS compared to not being a member. This result is in line with findings among
Norwegian high school students [24] but contributes with new in-depth information with regards to adults $[31,32]$. Also, in line with findings among high school students, although a higher physical activity level slightly increased the odds of using MEDS in males, our findings are of no coherence between use of MEDS and participation in organized sports [24]. Possible explanations might be the culture within fitness centers, where sale and use of such products are promoted [31], and where a focus on body appearance and shaping dominates, as in contrast to the performance, enjoyment, health, and social focus, more prominently promoted within organized sports $[29,30,41]$.

In males, reporting to exercise "to increase muscle mass" almost doubled the odds of using MEDS, which supports previous findings among male American fitness center members [32]. This might be expected, as those who aim to enhance muscle strength might be more receptive to advertisement claiming to give you a quick fix to improve muscle strength. In contrast, reporting to exercise "to increase endurance" reduced the odds of using MEDS, which is logical based on less intensive statements related to the products' effects on endurance, and the lower need of muscle building when aiming to improve endurance.

Finally, among males, we also found that being an exercise science student, as compared to other students, reduced the odds (OR: 0.47) of using MEDS. Our finding adds to current knowledge about differences in MEDS use between student groups. Firstly, because previous studies investigating differences between study programs have investigated differences in DS use in general, not specifically MEDS. Secondly, previous studies included nurse, medicine, and pharmaceutical students, as health-related students, who in contrast to exercise science students, do not have an educational background in sports nutrition and exercise physiology, 
and represent a very different health-related student group. The education of exercise science students provides them with sports nutrition and exercise knowledge which might have equipped them with lifestyle related media literacy. This argument only relies on the authors knowledge about exercise science students' curriculum, as we did not measure knowledge about supplements in our sample. However, one study supports our suggested explanation, by finding that students with higher media literacy were less likely to be DS users [14]. Also, exercise science students are exposed to a social environment which does not emphasize the need for supplements and special product in addition to, or at the expense of, real foods.

In female students, internalization of the athletic body ideal and exercising to increase muscle mass, being two highly coinciding elements, partly explained the variance in use of MEDS, after adjusting for all other variables in the regression model. The finding that females who internalized the athletic body ideal and exercised to increase muscle mass, were almost two times more likely to use MEDS, is novel among adults. However, it supports previous findings among Norwegian adolescent girls [24], and further underline that being occupied with improving physical appearance towards the muscular body ideal, takes part in explaining the use of MEDS.

Based on our finding that explanatory factors vary between genders, one could speculate whether males' habits related to use of MEDS are more affected by the environment they engage in (exercise context and study program), while females' habits are more strongly driven by their own demands and perceived needs to meet ideals (internalization). Importantly, in the discussion of explanatory factors for use of MEDS in both males and females, it is necessary to point out that the regression models for both genders only partly explained use of MEDS, which leaves room for further investigation of other explanatory factors which were not measured in this study. As an example, we were not able to assess energy and nutrient intake in the current study, and we only assessed current use of supplements without asking about duration and amount of use per supplement. The inclusion of these aspects of use might be especially important in future studies aiming to investigate and reflect upon potential long-term health consequences of such use. Also, considering our study design, we were not able to explore causation. Therefore, we cannot be sure whether students who are introduced to e.g., an exercise science program or a fitness center, develop specific behaviors in terms of using or not using MEDS, or whether individuals with specific characteristics are more prone to engage in such environments, and at the same time use such supplements. Longitudinal studies to better investigate direction of associations are needed in future research.

Importantly, our sample is comparable to previous student samples regarding age, BMI, and gender distribution within the sample. However, our sample differ by representing both exercise science students in addition to non-health and non-exercise science students. Also, in contrast to most studies, our sample included several universities, representing students from all parts of Norway.

\section{Strengths and limitations}

Our study included a large sample size, compared both male and female students, and included scarcely investigated explanatory factors for use of MEDS. Despite the large sample size, a low response rate may impair generalization, and well-known biases are related to selfreport of physical activity and exercise. Finally, based on our cross-sectional study design, cause-effect cannot be discussed.

\section{Perspectives}

Because higher education is assumed to lead to enhanced competence to practice source criticism and to make evidence-based lifestyle choices, the high frequency of DS and MEDS use among Norwegian university students, is surprising. Although we found less frequent DS and MEDS use compared to previous studies, the frequency of, reasons for, and explanatory factors for use, such as appearance, is of concern due to the potential negative physical and mental health effects. Variables related to body idealization are found to reduce well-being and mental health. Therefore, the use of MEDS can be related to a condition of less favorable mental health. Since studying exercise science seemed to result in lower frequency of MEDS use in our study, increased knowledge about health, exercise, and nutrition, might be important to prevent uncritical use of such supplements. Changes are also necessary within the fitness center industry, as this exercise context is known to promote idealization of specific body types in addition to promoting and selling MEDS.

\section{Conclusion}

Use of DS in general, and MEDS specifically, is frequent among Norwegian university students, with a higher frequency of MEDS use among males compared to females. Students most frequently used DS "to maintain or improve health", "to improve mental or physical performance", or "to increase muscle mass". In relation to use of MEDS, internalizing the athletic body ideal, 
being a fitness center member, study program, exercising to increase muscle mass and to improve endurance, and physical activity level, partly explained use of MEDS, with important differences between males and females.

\section{Abbreviations}

DS: Dietary supplements; MEDS: Muscle enhancing dietary supplements; SATA-Q: Social attitudes towards appearance questionnaire; OR: Odds ratio, SD: Standards deviation; Cl: Confidence interval; M: Mean; S.E.: Standard error

\section{Supplementary Information}

The online version contains supplementary material available at https://doi. org/10.1186/s40795-022-00510-1.

Additional file 1: Additional Table 1. Characteristics of, and differences between, male and female users and non-users of muscle enhancing dietary supplements.

Additional file 2: Additional Table 2. Associations with use of muscle enhancing dietary supplements.

\section{Acknowledgements}

The authors would like to thank all participating students and their respective universities for taking part in this study.

\section{Authors' contributions}

This study is a multidisciplinary cooperation between experts in exercise medicine from the Norwegian School of Sport Sciences, Oslo University Hospital, Østfold University College, and the University of Agder. CSB generated the original research idea, in collaboration with JSB. CSB, JSB, TFM, and MKT, collaborated on the study protocol and developed the questionnaire package. CSB collected the data, conducted the analyses, and wrote the first draft of the manuscript with important contributions from all co-authors with additional final approvals from all co-authors.

\section{Funding}

The Department of Sports Medicine at the Norwegian School of Sport Sciences financed gift cards which the participating students were in the draw for. There is no other funding to report. The Norwegian School of Sport Sciences did not interfere with study protocol, data collection, analyses, or manuscript preparations.

\section{Availability of data and materials}

The datasets generated and analyzed during the current study are not publicly available due to further use of the datafile in upcoming studies but are available from the corresponding author on reasonable request.

\section{Declarations}

\section{Ethics approval and consent to participate}

The study was conducted according to the World Medical Association Declaration of Helsinki and approved by the Norwegian Regional Committees for medical and health research ethics (No. 33532) and the Norwegian Centre for Research data (No. 978522). Informed consent was obtained from all subjects.

\section{Consent for publication}

Not applicable.

\section{Competing interests}

The authors declare that they have no competing interests.

\section{Author details}

'Department of Sports Medicine, Norwegian School of Sport Sciences, Sognsveien 220, N-0806 Oslo, Norway. ${ }^{2}$ Regional Department for Eating
Disorders, Division of Mental Health and Addiction, Oslo University Hospital, Postbox 4956, Nydalen, 0424 Oslo, Norway. ${ }^{3}$ Faculty of Health, Welfare and Organization, Østfold University College, PO 700, 1757 Halden, Norway. ${ }^{4}$ Faculty of Health and Sport Sciences, University of Agder, Postbox 422, 4604 Kristiansand, Norway.

Received: 25 June 2021 Accepted: 14 February 2022

Published online: 24 February 2022

\section{References}

1. $\mathrm{NIH}$. What you need to know. Dietary supplements: National institute of Health. Office of dietary supplements; 2020 [Available from: https://ods. od.nih.gov/factsheets/WYNTK-Consumer/.

2. Barnes K, Ball L, Desbrow B, Alsharairi N, Ahmed F. Consumption and reasons for use of dietary supplements in an Australian university population. Nutrition. 2016;32(5):524-30.

3. Block G, Jensen CD, Norkus EP, Dalvi TB, Wong LG, McManus JF, et al. Usage patterns, health, and nutritional status of long-term multiple dietary supplement users: a cross-sectional study. Nutr J. 2007;6(1):1-11.

4. Li K, Kaaks R, Linseisen J, Rohrmann S. Consistency of vitamin and/or mineral supplement use and demographic, lifestyle and health-status predictors: findings from the European Prospective Investigation into Cancer and Nutrition (EPIC)-Heidelberg cohort. Br J Nutr. 2010;104(7):1058-64.

5. Lieberman HR, Marriott BP, Williams C, Judelson DA, Glickman EL, Geiselman PJ, et al. Patterns of dietary supplement use among college students. Clin Nutr. 2015;34(5):976-85.

6. Valentine AA, Schumacher JR, Murphy J, Ma YJ. Dietary supplement use, perceptions, and associated lifestyle behaviors in undergraduate college students, student-athletes, and ROTC cadets. J Am Coll Health. 2018;66(2):87-97.

7. El Khoury D, Dwyer JJ, Fein L, Brauer P, Brennan S, Alfaro I. Understanding the use of dietary supplements among athlete and non-athlete university students: Development and validation of a questionnaire. Sports. 2019;7(7):166.

8. El Khoury D, Hansen J, Tabakos M, Spriet LL, Brauer P. Dietary Supplement Use among Non-athlete Students at a Canadian University: A Pilot-Survey. Nutrients. 2020;12(8):2284.

9. Begdache L, Kianmehr H, Heaney CV. College education on dietary supplements may promote responsible use in young adults. J Diet Suppl. 2018;17(1):67-80

10. Naqvi AA, Ahmad R, Elewi AAW, AlAwa AH, Alasiri MJ. Dietary supplement use among undergraduate male students in health and non-health cluster colleges of a public-sector university in Dammam. Saudi Arabia BMC Complement Altern Med. 2018;18(1):1-11.

11. Kobayashi E, Sato Y, Umegaki K, Chiba T. The prevalence of dietary supplement use among college students: a nationwide survey in Japan. Nutrients. 2017;9(11):1250.

12. Bailey RL, Gahche JJ, Miller PE, Thomas PR, Dwyer JT. Why US adults use dietary supplements. JAMA Intern Med. 2013;173(5):355-61.

13. Žeželj SP, Tomljanović A, Jovanović GK, Krešić G, Peloza OC, Dragaš-Zubalj $\mathrm{N}$, et al. Prevalence, knowledge and attitudes concerning dietary supplements among a student population in Croatia. Int J Environ Res Public Health. 2018;15(6):1058.

14. Yang SC, Hsu W-C, Chiang C-H. The Associations Among Individual Factors, Media Literacy, and Dietary Supplement Use Among College Students: Cross-Sectional Study. J Med Internet Res. 2020;22(8):e19056.

15. Guallar E, Stranges S, Mulrow C, Appel LJ, Miller ER III. Enough is enough: stop wasting money on vitamin and mineral supplements. Ann Intern Med. 2013;159(12):850-1.

16. Lentjes MA. The balance between food and dietary supplements in the general population. Proc Nutr Soc. 2019;78(1):97-109.

17. Marik PE, Flemmer M. Do dietary supplements have beneficial health effects in industrialized nations: what is the evidence? J Parenter Enter Nutr. 2012;36(2):159-68.

18. Maughan RJ. Quality assurance issues in the use of dietary supplements, with special reference to protein supplements. J Nutr. 2013;143(11):1843S-S1847. 
19. Hildebrandt T, Alfano L, Langenbucher JW. Body image disturbance in 1000 male appearance and performance enhancing drug users. J Psychiatr Res. 2010;44(13):841-6.

20. Ungdata BA. Nasjonale resultater 2017, NOVA Rapport 10/17. Oslo: NOVA; 2017.

21. Sundgot-Borgen C, Sundgot-Borgen J, Bratland-Sanda S, Kolle E, Torstveit MK, Svantorp-Tveiten KME, et al. Body appreciation and body appearance pressure in Norwegian university students comparing exercise science students and other students. BMC Public Health. 2021;21(1):532

22. Galioto R, Crowther JH. The effects of exposure to slender and muscular images on male body dissatisfaction. Body Image. 2013;10(4):566-73.

23. Tiggemann M, Zaccardo M. "Exercise to be fit, not skinny": The effect of fitspiration imagery on women's body image. Body Image. 2015;15:61-7.

24. Svantorp-Tveiten KE, Friborg O, Torstveit MK, Mathisen TF, SundgotBorgen C, Rosenvinge J, et al. Protein, Creatine, and DietingSupplements Among Adolescents:Use and Associations With EatingDisorder Risk Factors, Exercise-, andSports Participation, and ImmigrantStatus. Frontiers in sports and active living. 2021;3:1-11.

25. Rodgers RF, Slater A, Gordon CS, McLean SA, Jarman HK, Paxton SJ. A biopsychosocial model of social media use and body image concerns, disordered eating, and muscle-building behaviors among adolescent girls and boys. J Youth Adolesc. 2020;49(2):399-409.

26. Smolak L, Stein JA. A longitudinal investigation of gender role and muscle building in adolescent boys. Sex Roles. 2010;63(9-10):738-46.

27. Bakken, A.(2020). Ungdata 2020. National results.NOVA Report 16/20. Oslo: NOVA, OsloMet.

28. Deloitte. European Health \& Fitness Market Report 2016. EuropeActive/ Deloitte; 2016:1-144.

29. Mathisen TF, Aamodt J, Bratland-Sanda S, Sundgot-Borgen C, SvantorpTveiten KME, Sundgot-Borgen J. Body figure idealisation and body appearance pressure in fitness instructors. Front Psychol. 2020;11:3527.

30. Prichard I, Tiggemann M. Relations among exercise type, self-objectifcation, and body image in the fitness centre environment: The role of reasons for exercise. Psychol Sport Exerc. 2008;9(6):855-66.

31. Lacerda FMM, Carvalho WRG, Hortegal EV, Cabral NAL, Veloso HJF. Factors associated with dietary supplement use by people who exercise at gyms. Rev Saude Publica. 2015;49:63.

32. Morrison LJ, Gizis F, Shorter B. Prevalent use of dietary supplements among people who exercise at a commercial gym. Int J Sport Nutr Exerc Metab. 2004;14(4):481-92.

33. Pehlivan LT, Ozcan BA, Erem S, Ercan A, Akkaya I, Basarir A. Knowledge, attitude, and behaviour of physical education and sports students' about dietary supplements. Prog Nutr. 2020;22:1-7.

34. van der Kruk JJ, Jager-Wittenaar H, Nieweg RM, van der Schans CP. Do Dutch nutrition and dietetics students meet nutritional requirements during education? Public Health Nutr. 2014;17(6):1237-44.

35. Caspersen CJ, Powell KE, Christenson GM. Physical activity, exercise, and physical fitness: definitions and distinctions for health-related research. Public Health Rep. 1985;100(2):126.

36. Schaefer LM, Harriger JA, Heinberg LJ, Soderberg T, Kevin TJ. Development and validation of the sociocultural attitudes towards appearance questionnaire-4-revised (SATAQ-4R). Int J Eat Disord. 2017;50(2):104-17.

37. Hedges LV, Olkins I. Estimation of a Single Effect Size: Parametric and Nonparametric Methods. In: Hedges LV, Olkins I, editors. Statistical methods for meta-analysis. 1st ed. Orlando, Florida: Academic Press; 1985. p. 75-106.

38. Barland B, Tangen JO. Kroppspresentasjon og andre prestasjoner: en omfangsundersøkelse om bruk av doping (in Norwegian). Politihøgskolen; 2009. Report No.: 8278080658

39. DeLorme DE, Huh J, Reid LN, An S. Dietary supplement advertising in the US: a review and research agenda. Int J Advert. 2012;31(3):547-77.

40. Ek S. Gender differences in health information behaviour: a Finnish population-based survey. Health Promot Int. 2015;30(3):736-45.

41. Prichard I, Tiggemann M. Objectification in fitness centers: Self-objectification, body dissatisfaction, and disordered eating in aerobic instructors and aerobic participants. Sex Roles. 2005;53(1-2):19-28.

\section{Publisher's Note}

Springer Nature remains neutral with regard to jurisdictional claims in published maps and institutional affiliations.

Ready to submit your research? Choose BMC and benefit from:

- fast, convenient online submission

- thorough peer review by experienced researchers in your field

- rapid publication on acceptance

- support for research data, including large and complex data types

- gold Open Access which fosters wider collaboration and increased citations

- maximum visibility for your research: over $100 \mathrm{M}$ website views per year

At BMC, research is always in progress.

Learn more biomedcentral.com/submissions 